\title{
Psychological Aspects Associated with the Acquisition and Development of HPV Infection and its Repercussion on Quality of Life
}

\author{
L. Tomás-Aragonés ${ }^{* 1}$, A.B. Castillo-Amores ${ }^{1}$, C. Rodríguez-Cerdeira ${ }^{2}$ and S.E. Marrón-Moya ${ }^{1}$ \\ ${ }^{I}$ Department of Dermtology, Hospital Ernest Lluch of Calatayud \& Aragon Health Sciences Institute, Spain \\ ${ }^{2}$ Dermatology Department, CHUVI \& University of Vigo, Vigo, Spain
}

\begin{abstract}
A clear relationship between infection by Human Papillomavirus (HPV) and mental health problems does not seem to exist. Nonetheless, the presence of psychological symptoms - such as fear, guilt, shame and anxiety-are frequent in people who suffer the disease. A series of myths and false beliefs exist which may lead to great psychological discomfort. The diagnosis supposes putting into effect a process of adaptation. In this adaptation process to the disease, various defence mechanisms may appear. The importance of informing the patient - by the health professional - in a true and precise way, and allowing time for the patients to express their doubts about everything that is worrying them in order to face the emotional impact that giving the news to their partner and family may suppose should be highlighted. The disease leads to changes in lifestyle and quality of life. The aim is to help the patient in this process.
\end{abstract}

Keywords: HPV, psychological symptoms, quality life.

\section{INTRODUCTION}

The human papillomavirus (HPV) is the causal agent of the most widespread sexually transmitted viral infection in the world, with $25 \%$ of youngsters (men and women) being affected. Clinically it is associated with the development of cervical cancer in women and alterations in the epithelium of the sexual organs in both sexes. The best way to combat it is by early diagnosis and follow-up.

Despite there not being a clear relationship between HPV and mental health problems, there may be associated psychological problems, such as, for example, feelings of fear, guilt, shame and anxiety. Also intrusive thoughts have been described in relation to the human immunodeficiency virus (HIV), depressive symptoms and lowered quality of life in the psychosexual fields and in sleep quality [1].

HPV infection is related to a high state of anxiety at the time of informing the partner and family. For many people, this is the hardest aspect. Above all, women are worried about having to inform their partner and/or families of the results [2].

In order to better understand the associated psychological factors in the disease, it is important to highlight some myths and false beliefs that surround it [3].

1. I am the only person infected by HPV. Although there is more information daily in the mass media about the disease, this is still deficient. The majority of people have not heard of it until it is diagnosed. This lack of information, combined with the shame that having

*Address correspondence to this author at the Department of Dermatology, Hospital Ernest Lluch. of Calatayud \& Aragon Health Sciences Institute, Spain; Tel: 0034606973090; E-mail: luciatomas@cop.es caught a sexually transmitted disease may cause, makes the patient rarely share this experience with members of their environment and close friends and family. Thus, it often converts into a "secret", a load to be born, which the person affronts alone.

2. Only promiscuous people are exposed to sexually transmitted diseases. Even in the knowledge that there are 12 million North Americans carriers and an estimated 270 million carriers in the world, we continue believing that only those who do something "different" and "transgressional" are susceptible to becoming infected by this virus, since the most common and dangerous types of HPV are sexually transmitted [1]. In some way, this belief is related to the deep-rooted irrational idea in our culture that arises from considering the disease as a divine punishment, a consequence of our bad behaviour. In some studies, according to Doctor Nancy Kiviat, a researcher in the University of Washington, around $80 \%$ of people who have had only four sexual partners have been infected with HPV [3].

3. In a monogamous relationship, a diagnosis of HPV means that someone has been unfaithful. This myth is responsible for the confusion, ire and feelings of guilt which often appear after the diagnosis of HPV. The ability of HPV to remain latent for long periods of time, which may stretch to months or years, is, infrequently, taken into account. People have a false sense of immediateness and continuity of events. Not only do we join cause to effect, but we also believe they must, more or less, coincide in time. This, which in many moments of our lives is true, and which is a basic pillar of human learning, can also lead us astray, as in this case, making us reach erroneous conclusions about the genesis of the infection by 
HPV. The consequences may be highly relevant to the patient's life, causing crises with their partner and breakups.

4. "HPV equals uterine cancer". One of the characteristics of patients diagnosed of HPV is fear of suffering from cervical cancer. Although it is true that the presence of HPV increases the probability of having this form of cancer, it is important to explain to the patient that many strains of HPV exist, and that not all of them are related to cancer and, moreover, even in the case of the most damaging strains, there is not a lineal relationship between the pathologies. Types 16 and 18 are the most frequent high-risk viral strains in our environment and type 6 is the most frequent low-risk strain [1]. Perhaps the social repercussion of the vaccine and data given on its effectiveness have helped to potentate this association between HPV and cancer.

5. "If I have been infected by HPV I'll have it for the rest of my life, and it may reappear at any moment". It is true that at present no known cure exists for genital human papillomavirus. Nonetheless, recent studies from the Albert Einstein Faculty of Medicine from the University of Washington suggest that HPV may be totally eradicated from the body in people with a strong immunological system [4].

6. "If I always use a condom, I am not susceptible to becoming infected by HPV". Although the use of a condom is important since it minimizes contagion, it does not rule this out completely. Some authors such as Fuente and Mira from the University of Valencia cite this as having an effectiveness of $70 \%$ [5]. Others increase this figure slightly. What appears clear is that it is highly recommendable to use a condom since it is also important that the patient knows that although he is infected by one strain of HPV, he is not immune to being infected by whichever other strain he may come into contact with.

All these erroneous thoughts and myths about the disease can cause symptoms of anxiety and/or depression which may be perpetuated from the time of diagnosis until various weeks later, or in the worst cases may become chronic. In a study carried out in Milan with three groups of patients with genital HPV infection, a higher rate of anxiety and depression was observed than in the general public, although no specific mental illness could be found [6].

In this sense, the knowledge that HPV can be transmitted by sexual relationships may increase the feeling of guilt and stigmatization in women who are found positive [7].

In a great proportion of the patients, it is likely that, after the diagnosis, a period of adaptation to the disease ensues. At the beginning, the patients generally show signs of guilt, self inflicted reproaches or towards their partner, certain anxiety, hypochondria, etcetera.

Besides the symptoms of anxiety and depression, a series of psychological reactions exist which are common to the disease such as fear of solitude and personal devaluation, which may favour the presence of psychological illness [8].
In order to affront the diagnosis - and in order to reduce the anguish that this may suppose - some people put into effect a series of defence mechanisms. These are automatic psychological processes which protect the person from anxiety and the conciousness of external or internal threats or dangers. In principle, the defence mechanisms are damaging ways of affronting the anguish as they deform reality and get in the way of development. Nonetheless, they may be adaptive when they help the person to assimilate a particularly painful reality and when they potentate facing the problem. Some of the defence mechanisms which may appear in the first moments after knowing the diagnosis are given in Table 1.

\section{Table 1. Psychological Defence Mechanisms Against HPV}

Negation: consists in denying a painful or threatening reality, in this case the disease. Those aspects of the reality which are considered disagreeable are refused.

Repression: is a way to forget. That which causes annoyance at a conscious level is suppressed and relegated to the subconscious. This is used when the patient does not want to acknowledge the existence of a situation of frustration.

Rationalisation: is a subtle form of negation. People give themselves explanations which are untrue, but which serve to convince them of something and avoid whatever is causing them anxiety.

Projection: consists in blaming others, and the exterior world in general, with motivations which are refused or unknown in themselves.

Regression: consists in regressing to a time period before the development or old behavioural patterns, which were more satisfactory.

\section{OBJECTIVES}

The aim is to acheive acceptance of the disease, with the consequent changes of habits. In the case that no adaptation occurs, the most probable thing is that emotional illness has converted into symptoms of anxiety and/or depression and this will make it more difficult to introduce healthy behaviour into the patient's life.

It is important to educate the patient in strategies of actively and effectively facing the problem which will help them deal with the situation, reducing the symptoms of anxiety and/or depression and helping them to incorporate a certain feeling of control of the disease and its symptoms.

Lack of information may give rise to a range of emotions such as stigma, fear, guilt, impotence and anger. Thus the importance of informing well and reviewing the emotions that are aroused by the diagnosis in the patient [9].

High levels of self-perceived stress have been associated with a negative HPV immunological response in women with cervical dysplasia. This suggests that stress could be responsible for influencing the advance of cervical disease [10].

In order to help the patient in this process, we present two courses of action. We begin by reviewing the information that has to be given to the patient, paying special attention to the way it is given, to reduce anxiety and fear of the disease and to facilitate the patient's adaptation to the disease. Then we focus on the importance of working to 
change erroneous ideas about the disease when these are seen.

\section{Give True and Precise Information}

Health professionals attending patients with HPV infection should be sensitive to the psychosocial requirements, apart from attending to more clinical aspects [8].

Medical personnel should communicate the results without passing judgement and explore the personal interpretation that the patient has made in order to detect and talk about possible risks and stigma associated with the disease. In this way we will manage to minimize the adverse psychosocial consequences and promote positive sexual behaviour [11].

The use of simple technical language is important. The explanation must be clear, adapted to the patient, with concise and understandable language, avoiding entering into contradictions. Time should be left for the patient to have the opportunity to clarify their doubts. The process may be facilitated reassuring the patient with phrases such as: "It is absolutely normal that you don't know much about this virus, or even that people have given you erroneous ideas about it. Feel free to ask any questions, even if you think the answers are obvious".

An important aspect is to ask about the sexual behaviour of the patient in order to evaluate if it is necessary to suggest that this behaviour be modified. This, in itself, supposes an invasion of the patient's intimacy. Generally, patients of over 45 years old are more reluctant to talk about their sex lives than adolescents. The reason for the questions should be given from the start to reduce the patient's reluctance to talk.

\section{Cognitive Restructuring}

In order to destroy false beliefs cognitive therapy may be used in, at least, those patients with more serious problems such as insomnia and social isolation, or in those for whom the diagnosis of the viral infection has caused changes in their lives, for example a separation. In Table 2, the false beliefs are listed about the disease. Some of these beliefs have already been highlighted as myths about the disease, others are irrational beliefs peculiar to certain styles of coping, which are given below.

\section{Table 2. False Beliefs About HPV}

Nobody around me has HPV. It is neither common nor normal.
I have a shameful disease, peculiar to promiscuous people and those with
bad lifestyles.
I have done something to deserve HPV infection.
My partner has been cheating on me, how else could they have infected
me with HPV?
I have to find the moment I was infected.
If I have genital HPV I will finish up with uterine cancer.
I cannot do anything. Do as I may, I'll have HPV for the rest of my life.
I cannot have a partner because I would be afraid of infecting them with
the virus.

\section{CHANGES IN LIFESTYLE AND QUALITY OF LIFE}

Psychosocial stress, the negative ways of coping and the scarce social support, are related to health problems, including susceptibility to viral infection. Nonetheless, there are few epidemiological studies which have investigated these psychosocial factors associated to the risk of suffering cervical neoplasia [12]. In some cases child abuse has been related with the development of cervical neoplasia [13]. One study supplied evidence that "cases" of cervical neoplasia have more probability than the "controls" of being diagnosed of alexithymia [14]. Another study reported that some personality traits, especially anxiety, substance abuse and impulsiveness, are more common in cases of cervical cancer [15].

Genital infection by HPV may give rise to feelings of guilt and hypochondriac fears, as well as problems associated to sexual behaviour. In some cases, even after having received treatment, a high rate of sexual deterioration, fear of cancer and a worsening of the emotional relationship with the partner exists [16].

Many people diagnosed of HPV find themselves obliged to change some habits and modify their habitual lifestyle, influencing their quality of life. In a study carried out by $3 \mathrm{M}$ Pharmaceuticals on "personal communication", two thirds of the patients changed their habits due to genital warts. Among the most common changes were [17]:

- Use of condom.

- Longer periods of sexual abstinence.

- $\quad$ Lower number of sexual partners.

We must highlight the importance of healthy sex life habits. For example, the use of the condom - even if it does not protect $100 \%$ from new infections by HPV - it is important since it greatly reduces infections by other sexually transmitted diseases such as HIV, genital herpes or infection by Chlamydia. Comorbidity of these viruses increases the risk of oncogenic transformation and therefore of suffering cancer [11]. Other factors which increase the risk of cancer, and which, therefore, must be discussed with the patient are:

- Malnutrition. It would be advisable to ask the patient about their feeding habits and offer information of this type. The collaboration of professionals may be sought to prepare dietary guidelines [12].

- Smoking. It is advisable to insist on the importance of stopping smoking. The influence of tobacco on the neoplastic transformation of HPV infected cells has been shown in many studies. As was pointed out earlier, it would also be convenient here to count on the support of other professionals who help the patient to quit smoking.

\section{CONCLUSIONS}

To conclude, we would say that there were few studies on possible mental alterations which act as risk factors for contagion by HPV. We would like to point out here - as a conclusion - and only as possible research areas, some ideas. 
Firstly, the intervention in stress control improves mental health significantly, but its impact on immunological and hormonal processes has not been clearly identified. It would be necessary to continue investigating the importance that stress control has in these patients [18].

Secondly, If we analyse risk factors associated with HPV contagion, we reveal that many of them are present or may be present in certain psychopathologies such as the impulse control disorder [19]. This could be another line of investigation.

Finally, as a line of work to develop, workshops could be carried out in the context of the health promotion programs for youths in secondary schools. The objective of these workshops would be to give complete information about the disease, its consequences and risk factors for its possible infection.

\section{REFERENCES}

[1] Rose RC, Peake MR, Ennis N, Pereira DB, Antoni MH. Depressive symptoms, intrusive thoughts, sleep quality and sexual quality of life in women co-infected with human immunodeficiency virus and human papillomavirus. Chronic Illn 2005; 1: 281-7.

[2] McCaffery K, Waller J, Nazroo J, Wardle J. Social and psychological impact of HPV testing in cervical screening: a qualitative study. Sex Transm Infect 2006; 82: 169-74.

[3] Herzog TJ, Wright JD. The impact of cervical cancer in quality of life-the components and means for management. Gynecol Oncol 2007; 107: 572-7.

[4] "VPH Myth". ASHASTD. (American Social Health Association). 2009. Available at http://www.ashastd.org [last accessed 16 May 2009].

[5] Elena de la Fuente Díez, y Luz María Mira Ferrer. Las 47 preguntas sobre el virus del papiloma humano, VPH. Med Segur Trab 2008; 54: 212.

[6] Maggino T, Casadei D, Panontin E, et al. Impact of an HPV diagnosis on the quality of life in young women. Gynecol Oncol 2007; 107: 175-9.
[7] Waller J, Marlow LA, Wardle J. The association between knowledge of HPV and feelings of stigma, shame and anxiety. Sex Transm Infect 2007; 83: 155-9.

[8] Linnehan MJ, Groce NE. Counseling and educational interventions for women with genital human papillomavirus infection. AIDS Patient Care STDS 2000; 14: 439-45.

[9] Perrin KK, Daley EM, Naoom SF, et al. Women's reactions to HPV diagnosis: insights from in-depth interviews. Women Health 2006; 43: 93-110.

[10] Fang CY, Miller SM, Bovbjerg DH, et al. Perceived stress is associated with impaired T-cell response to HPV16 in women with cervical dysplasia. Ann Behav Med 2008; 35: 87-96.

[11] Kahn JA, Slap GB, Bernstein DI, et al. Personal meaning of human papillomavirus and Pap test results in adolescent and young adult women. Health Psychol 2007; 26: 192-200.

[12] Coker AL, Bond S, Madeleine MM, Luchok K, Pirisi L Psychosocial stress and cervical neoplasia risk. Psychosom Med 2003; 65: 644-51.

[13] Coker AL, Patel N, Krishnaswami S, Scvhmidt W, Richter DL. Chilhoood forced sex and cervical dysplasia among womwn prison inmates. Violence Against Women 1998; 4: 595-608.

[14] Todarello O, Casamassima A, Daniele S, et al. Alexithymia, inmunity and cervical intraepithelial neoplasia; replication. Psychother Psychosom 1997; 66: 208-13.

[15] Lalos A, Eisenmann M, Lalos O. Personality differences betwen endometrial and cervical cáncer patients in relation to sexual behavior. J Psychosom Obstertics Gynaecol 1997; 18: 53-8.

[16] Filiberti A, Tamburini M, Stefanon B, et al. Psychological asp ects of genital human papillomavirus infection: a preliminary report. J Psychosom Obstet Gynaecol 1993; 14: 145-52.

[17] De Palo G, Dexeus S, Chanen W. Patología y tratamiento del tracto genital inferior. $2^{\text {nd }}$ ed. Elsevier Masson 2007; pp. 1-41.

[18] Scott-Sheldon LA, Kalichman SC, Carey MP, Fielder RL. Stress management interventions for HIV+ adults: a meta-analysis of randomized controlled trials, 1989 to 2006. Health Psychol 2008; 27: 129-39.

[19] Kahn JA, Slap GB, Bernstein DI, et al. Psychological, behavioral, and interpersonal impact of human papillomavirus and Pap test results. J Womens Health (Larchmt) 2005; 14: 650-9. 